\title{
An exploration of strength use and its relationship with life satisfaction, positive self-beliefs and paranoid ideation
}

\author{
Kara McTiernan · Fiona Gullon-Scott · Robert Dudley
}

\begin{abstract}
Paranoid ideation is often preceded by negative interactions impacting on peoples' sense of self and wellbeing. The National Health Service in the United Kingdom is promoting wellbeing but there is a paucity of research. The authentic happiness theory and a strength intervention were drawn upon in a preliminary investigation of the relationships between strength-use, wellbeing and paranoia. In a cross-sectional study, students $(\mathrm{N}=531)$ completed measures of strength-use, wellbeing, self-beliefs and paranoia. Pearson's correlations, hierarchical multiple regression analysis, moderation analysis and mediation analysis were used to analyse the data. Strength-use was positively associated with life satisfaction and positive self-beliefs. There was a negative correlation between life satisfaction and paranoia, and higher positive self-beliefs were associated with lower paranoia. Paranoid ideation significantly predicted lower life satisfaction after controlling other symptoms of psychosis. Strength-use moderated the relationship between paranoia and life satisfaction. As hypothesised life satisfaction and positive self-beliefs mediated the relationship between strength-use and paranoia. The findings support delivering strength-use interventions to harness clients' wellbeing.
\end{abstract}

Keywords: positive psychology, strength-use, wellbeing, life satisfaction, positive cognitions, paranoid ideation

\section{Introduction.}

Mental illness and mental health are related but separate entities (Payton, 2009). The absence of a mental health difficultly does not necessarily equate with the presence of wellbeing (Keyes \& Martin, 2017). Similarly, clients with severe mental health difficulties and enduring physical health conditions can work towards and attain a sense of wellbeing (Barskova \& Oesterreich, 2009; Tse et al., 2016). Mental health services currently offer psychotherapies that largely target the alleviation of distress. However, to achieve the service vision of recovery and enhancing peoples' wellbeing (Tai et al., 2009) it is necessary to implement psychological models of wellbeing.

\subsection{Positive Psychology.}

Positive psychology is the scientific investigation of positive: subjective experiences, individual traits and institutions (Seligman \& Csikszentmihalyi, 2000). This paradigm includes the study of wellbeing and it has the corresponding theoretical underpinning and interventions 
(Seligman, 2002). This strength-based approach aligns with the humanist orientation of attending to the whole person, providing unconditional positive regard and supporting growth (Hefferon \& Boniwell, 2011). Clinicians actively foster mental health by drawing on positive psychology interventions (PPIs) to elicit and build positive emotions, cognitions and behaviours (Meyer et al., 2012). This facilitates the creation of a lasting repertoire of internal resources that enables coping in times of difficulty whilst indirectly reducing symptomology (Magyar-Moe, 2009). PPIs target wellbeing and focus on an individual's strengths as opposed to symptoms. PPIs are therefore transdiagnostic and can also be utilized by individuals not attending clinical services (Seligman, Rashid \& Parks, 2006).

\subsection{Positive psychology, subjective wellbeing and depression.}

One strand of positive psychology research investigates the relationship between subjective wellbeing (i.e. happiness) and people's strengths. The authentic happiness theory (Seligman, 2002) stipulates that positive emotion (the pleasant life), engagement (the engaged life) and meaning (the meaningful life) generate subjective wellbeing which in turn indirectly reduces a range of mental health difficulties, including depression. A consensus has emerged that subjective wellbeing consists of high positive affect, low negative affect and life satisfaction (Diener et al., 2017). PPIs, including the identification and the use of strengths are designed to activate the processes that result in subjective wellbeing. Peterson and Seligman (2004) have identified twenty-four strengths that are personal traits. Govindji and Linley (2007) view strengths as natural capabilities that individuals strive to use and that enable authentic expression that is invigorating. Thus, if a strength is present, the individual experiences a rejuvenating release of energy following its use (Peterson, 2006). Peterson proffers that mental health difficulties stem from the opposite, or the absence of, or the excess use of strengths and consequently a strength-based framework is a viable alternative to the diagnostic and statistical manual of mental disorders (Seligman, 2015). Seligman et al. (2005) investigated the 'identifying your strengths' and 'using your strengths' PPIs in a non-clinical sample over one week $(\mathrm{N}=411)$. The interventions led to higher levels of happiness and lower levels of depression compared to the control participants. These results were largely confirmed in replication studies by Gander et al. (2013) ( $\mathrm{N}=622)$ and Mongrain and Anselmo-Matthews (2012) ( $\mathrm{N}=344)$. However, the latter study, did not find a difference between the PPI and the control in reducing depression, albeit the control also induced positive cognition.

The connection between strength-based PPIs, subjective wellbeing and depression is further evidenced in non-clinical studies. The use of strengths increases positive affect (Wood et al., 2011), is associated with greater life satisfaction (Douglass \& Duffy, 2015) and reduces depression (Proyer et al., 2015). Clinically, PPIs were initially facilitated with clients with clinical depression, increasing positive affect (Pietrowsky \& Mitkutta, 2012) and reducing depression (Seligman et al., 2006). It is suggested that PPIs may have clinical utility for clients with other presentations with reduced positive affect, including psychosis (Dunn, 2017).

\subsection{Psychosis, subjective wellbeing and strength-based PPIs.}

Psychosis is a multifaceted experience that is characterised by a loss of touch with reality and it encompasses positive, negative and depressive symptoms (Sax et al., 1996). Psychosis is often a distressing and a debilitating experience (Barr, Ormrod \& Dudley, 2015) that impacts on a person's self-concept, confidence, hopes (Connell et al., 2015) self-esteem, social roles (Braehler \& Schwannauer, 2012) and it can result in a feeling of having lost oneself (Lester et al., 2011). 
Perhaps unsurprisingly, clients with psychosis have low levels of subjective wellbeing (Broyd, Jolley \& Johns, 2016).

To date, psychological interventions for psychosis have tended to be symptom based but are somewhat limited in their effectiveness. For instance, Cognitive Behavioural Therapy for psychosis (CBTp) has moderate benefit (Turner et al., 2014; Bighelli et al., 2018). To address this lack of efficacy, CBTp models have broadened to include strength-based formulations and interventions (Kuyken, Padesky \& Dudley, 2009). Beck, Himelstein and Grant (2019) also contend that there may be therapeutic gain in activating the positive schemata of clients with psychosis. It is suggested that strength-based Positive Psychotherapy, an approach that does not directly target symptoms, may contribute to enhancing the mental health of clients with psychosis (Hutton, 2016). This approach aligns with the concept of recovery and of attending to strengths, empowering clients, developing personal resources, reconnecting with one's sense of self and facilitating the emergence of a positive identity regardless of whether or not psychological difficulties persist (Higgins \& McBennett, 2007). It also involves providing a therapeutic space that does not centre on psychosis. The emerging evidence indicates that strength-based PPIs improve the wellbeing of clients with psychosis and reduce depression (Brownell et al., 2015; Sims et al., 2015; Schrank et al., 2016). However, Schrank et al. (2016) did not find that PPIs differed from the control across all wellbeing measures. Hall and Tarrier (2003) also demonstrated that eliciting and increasing clients' personal qualities improved self-esteem and significantly reduced positive symptoms, negative symptoms and general psychopathology. Thus, there is some evidence that PPIs may have a beneficial impact on wellbeing, depression, positive symptoms and negative symptoms of individuals with psychosis. However, the impact of strength-based interventions with clients with specific features of psychosis is not established. A strength-based approach may be suitable for clients with paranoid ideation.

\subsection{Strength-based PPIs and paranoid ideation.}

Paranoid ideation can be preceded by negative interpersonal processes including victimization (Jack \& Egan, 2018) and shame (Matos, Pinto, Gouveia \& Gilbert, 2014) that can impact on the person's sense of self (Sousa et al., 2015). Freeman et al. (2005) emphasize that the crux of paranoia is that people engage in negative self-evaluations and feel vulnerable and socially inferior to powerful harmful others. The severity of the threat from others increases along the paranoia hierarchy, whereby persecutory delusions are the severest form of paranoia (Freeman et al., 2005). The threat anticipation model (Freeman et al., 2002) sets out that persecutory delusions arise from multiple factors including previous experiences, precipitating events, maladaptive responses and cognitive biases that interact to influence how an individual interprets situations. Other models (Bentall, Kinderman \& Kaney, 1994) delineate that the external focus on others prevents negative thoughts about the self from reaching consciousness. This negative sense of self in paranoia is evidenced (Tiernan, Tracey \& Shannon, 2014). However, there is added complexity considering that fifty percent of clients with persecutory delusions also experience depression (Vorontsova, Garety \& Freeman, 2013), which is also associated with negative self-beliefs (Bradley \& Mathews, 1983). Nevertheless, Smith et al. (2006) found that negative self-evaluative beliefs were associated with persecutory delusions after controlling for depression and low self-esteem. Moreover, the activation of negative self-beliefs precedes and maintains positive symptoms (Jaya, Ascone \& Lincon, 2017). Research by Giester, Josephs and Swann (1996) underscores that the presence of negative self-beliefs can result in biased selfdeprecating cognitive processes that can impede the individual from engaging in positive self- 
evaluations. This includes individuals with psychosis not acknowledging personal strengths (Sims et al., 2015). There is also a negative correlation between non-clinical paranoia and selfkindness (Mills et al., 2007) and between clinical paranoid ideation and life satisfaction (Mankiewicz, Gresswell \& Turner, 2013). Furthermore, clients with clinical paranoia present with low levels of self-compassion and positive self-schemas (Collett et al., 2016). This suggests that there is a negative evaluation of one's self and others and an absence of positive cognition inherent in paranoid ideation. Ellett and Chadwick (2007) found that the generation of positive self-cognitions reduced non-clinical paranoia. Similarly, Atherton et al. (2016) reported that reinforcing personal characteristics reduced non-clinical paranoia. In adapting positive psychology theory and PPIs to paranoid ideation, Freeman et al. (2014) postulated that strengthbased PPIs would generate positive cognitions, reduce negative self-cognitions and thereby indirectly reduce paranoid ideation. Freeman et al. (2014) piloted a CBT and strength-based PPI for clinical paranoia, under the premise of developing client's confidence $(\mathrm{N}=30)$. The intervention led to significant improvements in wellbeing $(d=1.16)$, positive self-beliefs $(d=1.00)$, depression $(\mathrm{d}=0.68)$, a small non-significant reduction in negative self-beliefs $(\mathrm{d}=0.24)$ and a moderate non-significant reduction in paranoia $(\mathrm{d}=0.59)$. Meyer et al. (2012) also piloted a strength-based PPI with clients with schizophrenia that increased wellbeing and significantly reduced paranoia $(\mathrm{N}=16)$. There may therefore be merit in delivering strength-based PPIs to clients with paranoid ideation. However, it is unknown whether the benefits from the positive psychotherapy studies are specific to paranoid ideation or whether it is a result of a beneficial impact in fostering wellbeing or positive self-beliefs or influencing other difficulties such as depression.

\subsection{The present study.}

The current study aimed to investigate the relationships between strength-use, life satisfaction, positive self-beliefs and paranoid ideation in a non-clinical sample. In part this is to replicate previous findings but then in this context it explores the specific relationship between paranoia and wellbeing, and it examines in what ways strengths and positive beliefs may relate to paranoia. In keeping with previous research, it was expected that there would be a positive correlation between strengths-use and life satisfaction and between strengths-use and positive self-beliefs. Also replicating previous findings, it was expected that there would be a negative correlation between life satisfaction and paranoid ideation and between positive self-beliefs and paranoid ideation. It was hypothesised that paranoid ideation would be specifically associated with low life satisfaction, after accounting for other contributory factors. Additionally, it was proposed that strength-use would moderate the relationship between paranoid ideation and life satisfaction. Finally, it was hypothesised that life satisfaction and positive self-beliefs would mediate the relationship between strength-use and paranoid ideation.

\section{Method.}

\subsection{Participants.}

A single group cross sectional design was utilised. It was a requirement for participants $(\mathrm{N}=531)$ to be at least eighteen years of age, university students, literate and fluent in English.

\subsection{Measures.}

Strength Use Scale (SUS) (Govindji \& Linley, 2007): This is a fourteen item self-report measure of strength-use over the past month. Items (e.g. I am regularly able to do what I do best) are rated 
on a four-point scale ranging from (1) strongly disagree to (4) strongly agree. Previous research reported a Cronbach alpha of .87 (Rankin, 2015).

Satisfaction with Life Scale SWLS (Diener et al, 1985): This is a five item self-report measure of one's cognitive judgement of life over the past month. Items (e.g. I am satisfied with my life) are rated on a seven-point Likert scale ranging from (1) strongly disagree to (7) strongly agree. The instrument has a reported Cronbach alpha of 0.87 (Diener et al., 1985).

Positive and Negative Affect Schedule (PANAS) (Watson, Clark \& Tellegan, 1988): This is a twenty item self-report measure of positive affect (PA) and negative affect (NA) over the past month. Items are rated on a five-point Likert scale ranging from (1) not at all to (5) all of the time. The instrument has acceptable psychometric properties with Cronbach alphas of 89 for the PA scale and .85 for the NA scale (Crawford \& Henry, 2004).

Green Paranoid Thoughts Scales GPTS (Green, Freeman, Kuipers et al., 2008): This is a thirty-two item self-report measure of paranoid ideation over the past month. It consists of a social reference subscale (e.g. I spend time thinking about friends gossiping about me) and a social persecution subscale (e.g. certain individuals have had it in for me). Items are rated on a five-point Likert scale ranging from 1 (not at all) to 5 (totally). The instrument has a Cronbach alpha of .95 (Green et al., 2008).

Brief Core Schema Scales BCSS (Fowler et al., 2006): This is a twenty-four item self-report measure comprising of a; negative self-belief subscale (e.g. I am unloved), positive self-belief subscale (e.g. I am valuable) negative beliefs about others subscale (e.g. other people are hostile) and positive beliefs about others (e.g. other people are good) subscale. Endorsed items are rated on a four-point Likert scale ranging from (1) believe it slightly to (4) believe it totally. The research reports Cronbach alphas of .86 for the negative self-scale, .78 for the positive self-scale, .88 for the positive other subscale and .88 for the negative other subscale (Fowler et al., 2006).

Community Assessment of Psychic Experience CAPE-42 (Van Os, Verdoux \& Hanssen, 1999): This is a forty two item self-report measure of psychic experiences consisting of a positive dimension (e.g. Do you ever feel as if people seem to drop hints about you or say things with a double meaning?), a negative dimension (e.g. Do you ever feel that you are not a very animated person?) and a depressive dimension (e.g. Do you ever feel sad?). Endorsed items are rated on a fourpoint Likert scale ranging from (1) not distressed to (4) very distressed. In order to account for partial non-responses, a weighted score is calculated per dimension which is the sum score per dimension divided by the number of items filled in by the participant. Previous studies report Cronbach alphas of .84 for the positive dimension, .81 for the negative dimension and .76 for the depressive dimension (Mark \& Toulopoulou, 2016).

\subsection{Procedure.}

The research was approved by the Newcastle University Ethics Committee. Participants were recruited between September 2017 and January 2018 and were provided with; an information sheet, a consent sheet, a demographic sheet, the measures and a debriefing sheet. The information sheet set out that participation involved completing questionnaires designed to explore: strengths, life satisfaction, paranoid ideation, mood and self-beliefs. Participants identified their strengths with the Brief Strengths Test (BST) (Peterson, 2004) prior to completing the measures. The questionnaires were completed either online or in person and the participants received either course credits or they were entered into a prize draw. 


\subsection{Statistical analysis.}

The data was analysed using SPSS (Version 24, IBM Corp, Armonk, New York, America) and PROCESS software (Version 2.15, Hayes, 2012). Pearson's correlations explored the relationships between the variables. Hierarchical multiple regression analysis investigated if paranoid ideation specifically predicted life satisfaction. The Hayes moderation model 1 (Hayes, 2013) considered whether the use of strengths moderated the relationship between paranoid ideation and life satisfaction. The Hayes mediation model 4 (Hayes, 2013) explored the postulations of the authentic happiness theory (Seligman, 2002) and a strength-based PPI for paranoid ideation (Freeman et al., 2014). Hence, the indirect impact of life satisfaction and positive self-beliefs on the relationship between strength-use and paranoid ideation was investigated. There is no published literature investigating the relationship between these variables. The sample size for hierarchical multiple regression was calculated via the www.danielsoper.com website. A small to medium effect size was set for calculating power (0.04). There were seven predictors in Set $\mathrm{A}$ and one in Set B, the alpha level was .05, and the power .80, therefore a sample size of $\mathrm{N}=201$ was necessary.

In terms of missing data, a mean item score was assigned in instances where a participant had less than ten percent of the data missing on any of the scales. There was less than five percent missing on most of the measures, however for the CAPE (Van Os Verdoux \& Hanssen, 1999) there were two hundred and twelve cases missing on the positive dimension, one hundred and ninety six items missing on the negative dimension and one hundred and seventy one cases missing on the depressive dimension. Missing data was excluded on an analysis by analysis (pairwise basis). Seven extreme outliers (i.e. scores three standard deviations from the mean) were detected in the dataset, four in the negative self-belief BCSS subscale (Fowler et al., 2006) and one case in each of the CAPE subscales (Van Os Verdoux \& Hanssen, 1999). The outliers were retained. The skewness, kurtosis and the kolomogorove-smirnov values indicated a violation of the assumption of normality, yet the impact of this reduces in larger samples (Lumley, Diehr, Emerson \& Chen, 2002).

\section{Results}

\subsection{Descriptive statistics.}

The demographics of the sample are illustrated in table 1 . The majority of the sample were; aged between 18-21 years, single, white and undergraduate students. 
Table 1: Demographic of the Sample $(\mathrm{N}=531)$

\begin{tabular}{|c|c|c|}
\hline Variable & & $\begin{array}{l}\text { University } \\
\text { Students n (\%) }\end{array}$ \\
\hline \multicolumn{3}{|l|}{ Gender } \\
\hline & Male & $164(30.90)$ \\
\hline & Female & $367(69.10)$ \\
\hline \multicolumn{3}{|l|}{ Age } \\
\hline & $18-21$ & $442(83.20)$ \\
\hline & $22-39$ & $89(16.80)$ \\
\hline & $40-100$ & $0(0)$ \\
\hline \multicolumn{3}{|c|}{ Relationship status } \\
\hline & Single & $442(83.20)$ \\
\hline & Cohabiting & $21(4.00)$ \\
\hline & Married & $14(2.60)$ \\
\hline & Other & $54(10.20)$ \\
\hline \multicolumn{3}{|l|}{ Ethnicity } \\
\hline & White & $429(80.80)$ \\
\hline & Black & $11(2.10)$ \\
\hline & Asian & $67(12.60)$ \\
\hline & Other & $24(4.50)$ \\
\hline \multicolumn{3}{|c|}{ Student status } \\
\hline & Undergraduate & $449(84.60)$ \\
\hline & Postgraduate & $82(15.40)$ \\
\hline \multicolumn{3}{|l|}{ Faculty } \\
\hline & Humanities and social science & $216(40.70)$ \\
\hline & Medical science & $212(39.90)$ \\
\hline & Science, agriculture and engineering & $103(19.40)$ \\
\hline \multicolumn{3}{|c|}{ Data Collected } \\
\hline & Online & $250(47.08)$ \\
\hline & In person & $281(52.92)$ \\
\hline
\end{tabular}

Note: The demographic divisions align with categories provided by the Higher Education Statistics Agency (2018) and by Newcastle University (2018).

The range scores, means, standard deviations and Cronbach's alphas of the measures are detailed in table 2 
Table 2: The range scores, mean scores, standard deviations and Cronbach's alphas.

\begin{tabular}{lllll}
\hline Measure & $\begin{array}{l}\text { Reported } \\
\text { Range }\end{array}$ & $\begin{array}{l}\text { Norm } \\
\text { mean (SD) }\end{array}$ & $\begin{array}{l}\text { Reported } \\
\text { mean (SD) }\end{array}$ & $\alpha$ \\
\hline SUS & $16-56$ & $44.66(5.70)$ & $40.68(6.48)$ & .90 \\
SWLS & $5-35$ & $23.50(6.43)$ & $24.50(6.13)$ & .86 \\
PANAS PA & $10-50$ & $32.0(7.00)$ & $33.44(6.90)$ & .84 \\
PANAS NA & $10-50$ & $19.50(7.00)$ & $24.11(7.65)$ & .86 \\
Total GPTS & $32-143$ & $48.8(18.70)$ & $58.68(21.10)$ & .95 \\
GPTS SP & $16-74$ & $22.1(9.20)$ & $24.66(11.20)$ & .94 \\
GPTS SR & $16-72$ & $26.8(10.40)$ & $34.08(12.07)$ & .91 \\
BCSS PSB & $0-24$ & $10.20(4.23)$ & $12.44(5.60)$ & .81 \\
BCSS NSB & $0-22$ & $3.55(3.55)$ & $2.70(3.82)$ & .90 \\
Cape PD & $0.67-7$ & $1.42(0.26)$ & $2.01(0.72)$ & .89 \\
Cape ND & $0.89-5$ & $1.62(0.37)$ & $2.03(0.60)$ & .90 \\
Cape DD & $1-6$ & $1.72(0.40)$ & $2.40(0.72)$ & .84 \\
\hline
\end{tabular}

Note: SUS=Strength Use Scale; SWLS =Satisfaction with Life Scale; PANAS PA= Positive and Negative Affect Schedule Positive Affect; PANAS NA= Positive and Negative Affect Schedule, Negative Affect; BCSS PSB= Brief Core Schema Scale, Positive Self Belief; BCSS NSB= Brief Core Schema Scale, Negative Self Belief; Total GPTS= Green Paranoid Thoughts Scales; GPTS SP= Green Paranoid Thoughts Social Persecution; GPTS SR= Green Paranoid Thoughts Social Reference; CAPE PA= Community Assessment of Psychic Experience, Positive Dimension; CAPE ND= Community Assessment of Psychic Experience, Negative Dimension; CAPE DD= Community Assessment of Psychic Experience, Depressive Dimension.

The mean scores on the SUS, SWLS, PANAS-PA, BCSS and CAPE were broadly consistent with the findings of previous studies (Watson et al., 1988; Fowler et al., 2006; Pavot \& Diener, 2009; Pfeifer et al., 2009; Rankin, 2015). The level of negative affect was higher than previous samples (Watson et al., 1988). The paranoid ideation score was also above other non-clinical norms, yet below the clinical cut off score of 101 (Green et al., 2008).

\subsection{Pearson's correlations.}

Pearson's correlations explored the relationships between strength-use, life satisfaction, positive self-beliefs, paranoid ideation and other measures. As illustrated in table 3, there were positive correlations between strengths-use and life satisfaction and between strengths-use and positive self-beliefs. Similarly, there was a negative correlation between life satisfaction and paranoid ideation and between positive self-beliefs and paranoid ideation. 
Table 3. Pearson correlations for all measures.

\begin{tabular}{|c|c|c|c|c|c|c|c|c|c|c|c|c|}
\hline & SUS & SWLS & PA & NA & $\begin{array}{c}\text { BCSS } \\
\text { PSB }\end{array}$ & $\begin{array}{c}\text { BCSS } \\
\text { NSB }\end{array}$ & GPTS & $\begin{array}{c}\text { GPTS } \\
\text { SP }\end{array}$ & $\begin{array}{c}\text { GPTS } \\
\text { SR }\end{array}$ & $\begin{array}{c}\text { CAPE } \\
\text { PD }\end{array}$ & $\begin{array}{c}\text { CAPE } \\
\text { ND }\end{array}$ & $\begin{array}{c}\text { CAPE } \\
\text { DD }\end{array}$ \\
\hline SUS & 1 & & & & & & & & & & & \\
\hline SWLS & $.38^{* *}$ & 1 & & & & & & & & & & \\
\hline PA & $.46^{\prime \prime}$ & $.54^{\prime \prime}$ & 1 & & & & & & & & & \\
\hline NA & $-.15^{\prime \prime}$ & $-.39^{\prime \prime}$ & $-.22^{\prime \prime}$ & 1 & & & & & & & & \\
\hline BCSS PSB & $.50^{\circ \prime}$ & $.51^{\prime \prime}$ & $.54^{\prime \prime}$ & $-.33^{\prime \prime}$ & 1 & & & & & & & \\
\hline BCSS NSB & $-.32^{* \prime}$ & $-.48^{\prime \prime}$ & $-.35^{\prime \prime}$ & $.38^{\prime \prime}$ & $-.39^{\prime \prime}$ & 1 & & & & & & \\
\hline GPTS & $-.16^{*}$ & $-.35^{\prime \prime}$ & $-.22^{\prime \prime}$ & $.53^{\prime \prime}$ & $-.24^{\prime \prime}$ & $.41^{\prime \prime}$ & 1 & & & & & \\
\hline GPTS SP & $-.09^{\circ}$ & $-.28^{\prime \prime}$ & $-.18^{\prime \prime}$ & $.42^{\prime \prime}$ & $-.15^{\prime \prime}$ & $.30^{\prime \prime}$ & $.90^{\prime \prime}$ & 1 & & & & \\
\hline GPTS SR & $-.20^{\prime \prime \prime}$ & $-.35^{\prime \prime}$ & $-.22^{\prime \prime}$ & $.53^{\prime \prime}$ & $-.28^{\prime \prime}$ & $.43^{\prime \prime}$ & $.91^{\prime \prime}$ & $.64^{\prime \prime}$ & 1 & & & \\
\hline CAPE PD & $-.23^{m x}$ & $-.22 "$ & $-.19^{\prime \prime}$ & $.29^{\prime \prime}$ & $-.28^{\prime \prime}$ & $.29^{\prime \prime}$ & $.21^{\prime \prime}$ & $.15^{\prime \prime}$ & $.23^{\prime \prime}$ & 1 & & \\
\hline CAPE ND & $-.25^{* *}$ & $-.19^{\prime \prime}$ & $-.17^{\prime \prime}$ & $.34^{\prime \prime}$ & $-.16^{\prime \prime}$ & $.35^{\prime \prime}$ & $.25^{\prime \prime}$ & $.19^{\prime \prime}$ & $.26^{\prime \prime}$ & $.45^{\prime \prime}$ & 1 & \\
\hline CAPE DD & $-.21^{* *}$ & $-.16^{\prime \prime}$ & -.07 & $.31^{\prime \prime}$ & $-.11^{\prime}$ & $.32 "$ & $.23^{\prime \prime}$ & $.18^{\prime \prime}$ & $.23^{\prime \prime}$ & $.38^{\prime \prime}$ & $.52^{* *}$ & 1 \\
\hline
\end{tabular}

Note: SUS=Strength Use Scale; SWLS =Satisfaction with Life Scale; PANAS PA= Positive and Negative Affect schedule, Positive Affect; PANAS NA= Positive and Negative Affect Schedule Negative Affect; BCSS PSB= Brief Core Schema Scale, Positive self-belief; BCSS NSB= Brief Core Schema Scale, Negative self-belief; Total GPTS= Green Paranoid Thoughts Scales; GPTS $\mathrm{SP}=$ Green Paranoid Thoughts Scales; Social persecution; GPTS SR= Green Paranoid Thoughts Scales; Social reference; CAPE PA= Community Assessment of Psychic Experience, Positive Dimension; CAPE ND= Community Assessment of Psychic Experience, Negative Dimension; CAPE DD=Community Assessment of Psychic Experience, Depressive Dimension * Correlation is significant at the 0.01 level (2-tailed).

- Correlation is significant at the 0.05 level (2-tailed).

\subsection{Hierarchical multiple regression.}

A hierarchical multiple regression examined if paranoid ideation specifically accounted for lower life satisfaction after controlling for other variables. As depicted in table 4, age and gender did not significantly account for variance in life satisfaction. The addition of strength-use, in block 2 increased the total variance explained by the model as a whole to $15 \%\left(R^{2}=.15, F(3,303)\right.$ $=17.67, \mathrm{p}<.01)$. Positive, negative and depressive dimensions were subsequently entered in block 3 and accounted for $17 \%$ of the variance in life satisfaction $\left(R^{2}=.17, F(6,300)=10.25, p<.01\right)$. Strength-use remained the only variable to make a unique statistically significant contribution (beta $=.32, \mathrm{P}<.01$ ). To increase specificity to investigating the predictive value of paranoia on life satisfaction, paranoid ideation was entered into the model in a fourth block that added paranoia after all previous variables. The total model accounted for $24 \%$ of the variance in life satisfaction $\left(\mathrm{R}^{2}=.24, \mathrm{~F}(7,299)=13.81, \mathrm{p}<.01\right)$. In this instance both strength-use (beta=.36, $\left.\mathrm{p}<.01\right)$ and paranoid ideation (beta $=-.08, \mathrm{p}<.01$ ) made a significant contribution. The tolerance values of the model were greater than .05, the VIF values were less than 10 and the Durban Watson test was 1.86. This indicated no issues with multicollinearity or autocorrelation. 
Table 4: Hierarchical multiple regression predicting life satisfaction.

\begin{tabular}{|c|c|c|c|c|c|c|c|c|c|}
\hline $\begin{array}{l}\text { Predictor } \\
\text { variables }\end{array}$ & $\mathbf{R}^{2}$ & $\begin{array}{l}\text { Adjusted } \\
\mathbf{R}^{2}\end{array}$ & $\mathbf{R}^{2}$ & $\mathbf{F}$ & B & $\begin{array}{l}\text { Std. } \\
\text { error }\end{array}$ & $\beta$ & $\mathrm{T}$ & Sig. \\
\hline \multicolumn{10}{|l|}{ Block 1} \\
\hline & .00 & -.01 & .00 & .30 & & & & & \\
\hline Age & & & & & .12 & .96 & .01 & .13 & .90 \\
\hline Gender & & & & & -.59 & .76 & -.06 & -.78 & .44 \\
\hline \multicolumn{10}{|l|}{ Block 2} \\
\hline $\begin{array}{l}\text { Strength } \\
\text { use }\end{array}$ & .15 & .14 & .15 & $17.67^{*}$ & .36 & .05 & .39 & 7.23 & .00 \\
\hline \multicolumn{10}{|l|}{ Block 3} \\
\hline $\begin{array}{l}\text { Positive } \\
\text { symptoms }\end{array}$ & .17 & .15 & .02 & $10.25^{*}$ & -.98 & .52 & -.12 & -1.91 & .06 \\
\hline $\begin{array}{l}\text { Negative } \\
\text { symptoms }\end{array}$ & & & & & -.47 & .67 & -.05 & -.69 & .49 \\
\hline $\begin{array}{l}\text { Depressive } \\
\text { symptoms }\end{array}$ & & & & & -.18 & .54 & -.02 & -.34 & .73 \\
\hline Block 4 & & & & & & & & & \\
\hline $\begin{array}{l}\text { Paranoid } \\
\text { ideation }\end{array}$ & .24 & .23 & .07 & $13.81^{*}$ & -.08 & .02 & -.29 & -5.42 & .00 \\
\hline
\end{tabular}

* Significant $\mathrm{p}<.01$

\subsection{Moderation analysis.}

Moderation analysis found that strength-use moderated the relationship between paranoid ideation and life satisfaction.

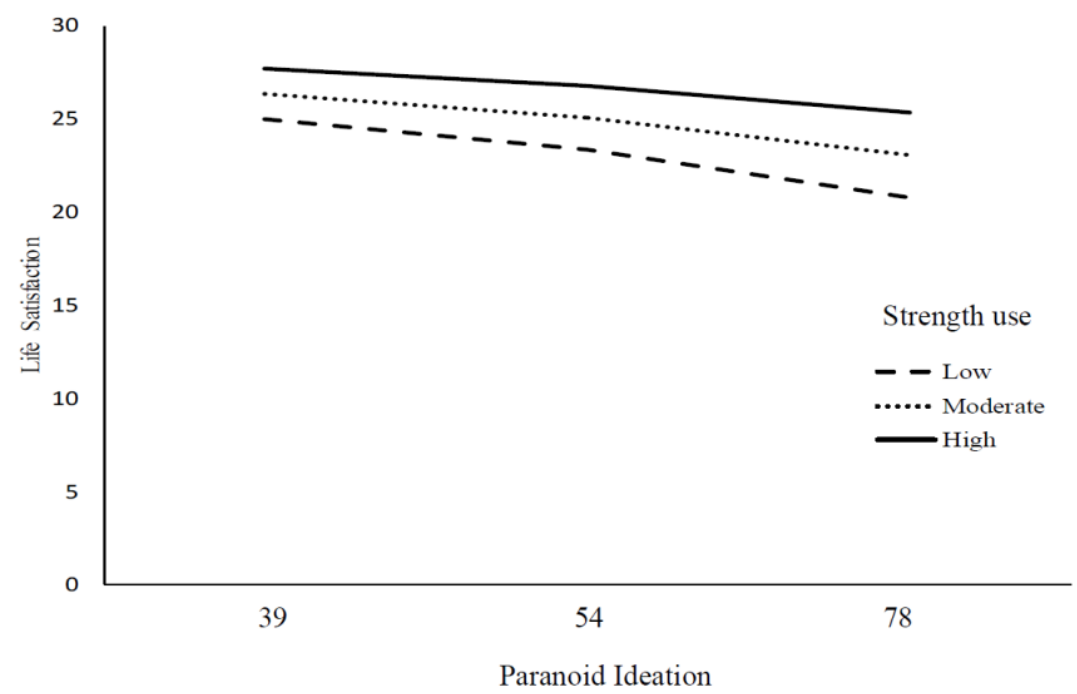

Figure 1: Simple slopes equation of the regression of life satisfaction on paranoid ideation at three levels of strength-use. 
The linear model of predictors of life satisfaction is outlined in table 5 . This illustrates that strength-use moderated the relationship between paranoid ideation and life satisfaction, $b=.00$ $(.00, .01)$.

Table 5: Linear model of predictors of life satisfaction.

\begin{tabular}{lcccc}
\hline & $B$ & $S E B$ & $T$ & $P$ \\
\hline Constant & 26.57 & 4.21 & 6.31 & $<.01$ \\
& $(18.30,34.84)$ & & & \\
Paranoid Ideation & -.25 & .06 & -3.87 & \\
& $(-.37,-.12)$ & & & .01 \\
Strength Use & .08 & .10 & .75 & \\
& $(-.12, .27)$ & & & .01 \\
Paranoid Ideation $X$ & .00 & .00 & 2.55 & \\
Strength Use & $(.00, .00)$ & & & \\
\hline
\end{tabular}
Note: $R^{2}=.24$.

Figure 1 illustrates the simple slopes equation of the regression of life satisfaction on paranoid ideation at three levels of strength-use. Under lower levels of paranoid ideation there was a small difference in life satisfaction depending on strength-use. However, as paranoid ideation increased participants with higher levels of strength-use reported greater levels of life satisfaction.

\subsection{Mediation analysis.}

Mediation analysis investigated the indirect impact of life satisfaction and positive selfbeliefs on the relationship between strength-use and paranoid ideation. Thereby investigating the mechanism by which strengths-use may reduce paranoid ideation. Mediation analysis was conducted based on 5,000 bootstrapped samples using bias corrected and accelerated 95\% confidence intervals (CIs). As portrayed in figure 2, strength-use had a significant, direct path to paranoid ideation $(b=-.16 \mathrm{SE}=.14, \mathrm{p}<.01)$ and life satisfaction $(b=.38 \mathrm{SE}=.038, \mathrm{P}<.01)$. Life satisfaction had a significant direct path to paranoid ideation $(b=-.35 \mathrm{SE}=.14, \mathrm{P}<.01)$. When life satisfaction was entered into the model, strength-use had a reduction with paranoid ideation and the reduction in this relation was significant $(\mathrm{SE}=.09 \mathrm{CI}=-.61,-.27)$ and statistically different from zero, demonstrated by a $95 \%$ bias corrected bootstrap confidence interval that does not include zero. Thus, life satisfaction mediated the relationship between strength-use and paranoid ideation. The indirect effect was -.42 . The total model was significant $\left(R^{2}=.13, F(2,520)=37.08\right.$, $\mathrm{p}<.01$ ) and explained $13 \%$ of the variance in paranoid ideation.

In a second analysis, detailed in figure 3 , strength-use also had a significant direct path to positive self-beliefs $(b=.50, \mathrm{SE}=.03, \mathrm{P}<.01)$. There was a direct path from positive self-beliefs to paranoid ideation $(b=-.24, \mathrm{SE}=.17 \mathrm{P}<.01)$. When positive self-beliefs was entered into the second model, strength-use had a reduction with paranoid ideation and the reduction in this relation was significant $(\mathrm{SE}=.10 \mathrm{CI}=-.55,-.18)$ and statistically different from zero, demonstrated by a $95 \%$ 
bias-corrected bootstrap confidence interval that does not include zero. Therefore, positive selfbeliefs mediated the relationship between strength-use and paranoid ideation. The indirect effect was -.35 . The total model was significant $\left(\mathrm{R}^{2}=.06, \mathrm{~F}(2,485)=16.01, \mathrm{p}<.01\right.$ and explained $6 \%$ of the variance in paranoid ideation.

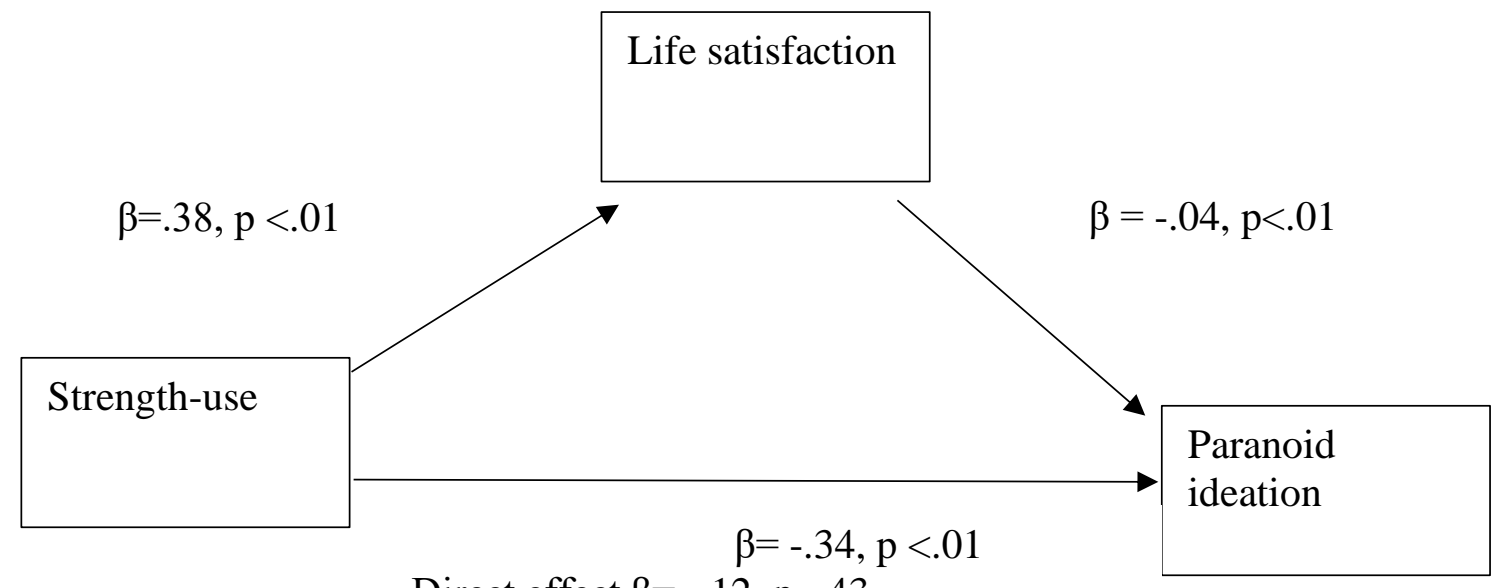

Direct effect $\beta=-.12 \mathrm{p}=.43$

Indirect effect $\beta=-.42(\mathrm{CI}-.61,-.26)$

Figure 2: Mediation analysis with paranoid ideation as the outcome measure in a non-clinical sample.

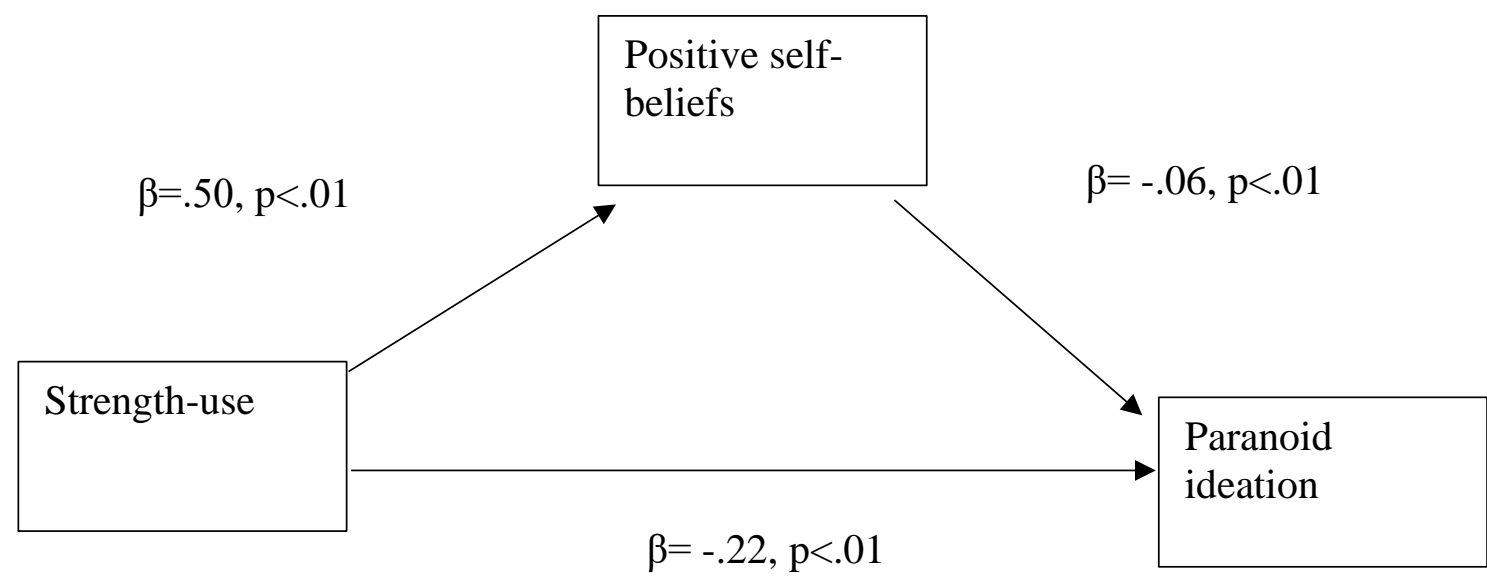

Direct effect $\beta=-.18, p=.28$

Indirect effect $\beta=-.35$ (CL $-.55,-.18)$

Figure 3: Mediation analysis with paranoid ideation as the outcome measure in a non-clinical sample.

\section{Discussion}

4.1. Summary of the main findings.

This study investigated the relationships between strength-use, life satisfaction, positive selfbeliefs and paranoid ideation. All of the hypotheses were supported. Strength-use was positively 
associated with greater life satisfaction, which echoes the findings of Douglass and Duffy (2015). Similarly, there was the expected negative correlation between life satisfaction and paranoid ideation, which reiterates the findings of Mankiewicz, Gresswell and Turner (2013). Positive selfbeliefs were negatively associated with paranoid ideation, which corresponds with the findings of Mills et al. (2007) and Collett et al. (2016). As hypothesized, paranoid ideation negatively predicted life satisfaction after controlling for other positive, negative and depressive symptoms of psychosis. This suggests that there is specificity in paranoid ideation reducing life satisfaction. The use of strengths was found to moderate the relationship between paranoid ideation and life satisfaction. The postulations of the authentic happiness theory (Seligman, 2002) and a strengthbased PPI for paranoid ideation (Freeman et al., 2014) were subsequently explored via mediation analysis. Life satisfaction did mediate the relationship between strength-use and paranoid ideation and the total model accounted for a significant variance in paranoid ideation. This finding is consistent with the authentic happiness theory (Seligman, 2002) and the work of Meyer et al. (2012) which found that strength-based PPIs increased wellbeing and decreased paranoid ideation. Strengths-use also predicted positive self-cognitions, which in turn meditated the relationship between strength-use and paranoid ideation. The total model accounted for a significant variance in paranoid ideation. This aligns with the findings of Freeman et al. (2014). It is noteworthy that strength-use was a greater predictor of positive self-beliefs compared to positive self-beliefs negatively predicting paranoid ideation. This aligns with the primary function of PPIs which is to engage individuals in adaptive psychological processes that enhance wellbeing.

\subsection{Strengths and limitations of the research.}

In considering the strengths of the study, it implemented non-clinical measures that were specific to strength-use, life satisfaction, positive self-beliefs, features of psychosis and paranoid ideation. The sample size was also large, allowing for robust associations to be investigated. The limitations of the research include, that a cross sectional design was utilized that does not enable a causal link to be established between the constructs and it also does not control for extraneous variables (Maxwell \& Cole, 2007). Additionally, participants were primed to identify their strengths with the BST (Peterson, 2004), which aligns with the character strengths as delineated by Peterson and Seligman (2004), prior to completing the SUS (Govindji \& Linley, 2007). However, the influence of the first measure on the second measure is only assumed. Another limitation is the recruitment of a non-clinical sample, whereby the level of paranoid ideation was lower than that of a clinical population thereby limiting the generalisability of the findings. It is also noteworthy that the analysis revealed a significant association between the use of strength and positive affect. However, a detailed analysis of this aspect of wellbeing was beyond the scope of the current paper.

\subsection{Clinical implications and conclusion.}

The findings provide additional evidence of the association between strength-use and life satisfaction. This has clinical implications in offering strength-based interventions under the premise of harnessing clients' wellbeing. The association between strength-use and positive selfbeliefs warrants further research, particularly in light of the absence of positive self-cognitions in paranoid ideation. The research found specificity in paranoid ideation reducing life satisfaction. This provides a rationale for offering strength-based interventions to clients with paranoid ideation. Moreover, the use of strengths moderated the relationship between paranoid ideation 
and life satisfaction, which supports the use of this particular PPI. In considering the theoretical underpinnings of the study, the results support both the authentic happiness theory (Seligman, 2002) and the postulations of a strength-based PPI for paranoid ideation (Freeman et al., 2014). The findings indicate that the use of strengths may activate other forms of positive cognitions other than life satisfaction. However, in order to accurately test these models, further work with clients presenting with clinical paranoid ideation is clearly required. One approach could be to facilitate clients to use personal strengths and to complete measures of strength, wellbeing and paranoia pre and post intervention. Positive psychotherapy entails, facilitating clients to become conscious of a personal strength prior to its use and setting out or completing the associated behaviour in sessions (Rashid, 2015). A longitudinal design would also establish a temporal precedence to clarify the relationship between the constructs. However, overall the preliminary findings indicate that PPIs may benefit individuals with paranoid ideation in addition to clients with depression. It therefore offers preliminary evidence that strength-based interventions could contribute to the mental health of clients with paranoid ideation attending mental health services.

\section{Authors}

Kara McTiernan

Newcastle University

Cumbria, Northumberland, Tyne and Wear NHS Foundation Trust

karamctiernan@gmail.com

Fiona Gullon-Scott

Newcastle University

Robert Dudley

Newcastle University

Cumbria, Northumberland, Tyne and Wear NHS Foundation Trust

\section{Publishing Timeline}

Received 24 March 2019

Accepted 10 March 2020

Published 1 June 2020

\section{References}

Atherton, S., Antley, A., Evans, N., Cernis, E., Lister, R., Dunn, G., \& Freeman, D. (2016). Self-confidence and paranoia: an experimental study using an immersive virtual reality social situation. Behavioural and Cognitive Psychotherapy, 44, 1, 56-64. doi:10.1017/S1352465814000496.

Barr, K., Ormrod, J., \& Dudley, R. (2015). An exploration of what service users value about early intervention in psychosis services. Psychology and Psychotherapy: Theory, Research and Practice, 88, 4, 468480. doi: 10.1111/papt.12051.

Barskova, T. \& Oesterreich, R. (2009). Post traumatic growth in people living with a serious medical condition and its relations to physical and mental health: A systematic review. Disability and Rehabilitation, 31, 21, 1709-1733. doi: 10.1080/09638280902738441.

Beck, A. T., Himelstein, R., \& Grant, P. M. (2019). In and out of schizophrenia: Activation and deactivation of the negative and positive schemas. Schizophrenia Research, 203, 55-61. doi: 10.1016/j.schres.2017.10.046.

Bentall, R. P., Kinderman, P., \& Kaney, S. (1994). The self, attributional processes and abnormal beliefs: towards a model of persecutory delusions. Behaviour Research and Therapy, 32, 3, 331-341. doi: 10.1016/0005-7967(94)90131-7. 
Bighelli, I., Salanti, G., Huhn, M., Schneider-Thoma, J., Krause, M., Reitmeir, C.,... \& Furukawa, T. A. (2018). Psychological interventions to reduce positive symptoms in schizophrenia: systematic review and network meta-analysis. World psychiatry, 17, 3, 316-329. doi: 10.1002/wps.20577.

Bradley, B. \& Mathews, A. (1983). Negative self-schemata in clinical depression. British Journal of Clinical Psychology, 22, 3, 173-181. doi: 10.1111/j.2044-8260.1983.tb00598.x.

Braehler, C. \& Schwannauer, M. (2012). Recovering an emerging self: Exploring reflective function in recovery from adolescent-onset psychosis. Psychology and Psychotherapy: Theory, Research and Practice, 85,1, 48-67. doi: 10.1111/j.2044-8341.2011.02018.x.

Brownell, T., Schrank, B., Jakaite, Z., Larkin, C., \& Slade, M. (2015). Mental health service user experience of positive psychotherapy. Journal of Clinical Psychology, 71, 1, 85-92. doi: 10.1002/jclp.22118.

Broyd, A., Jolley, S., \& Johns, L. (2016). Determinants of subjective well-being in people with psychosis referred for psychological therapy in South London. British Journal of Clinical Psychology, 55, 4, 429-440. doi: $10.1111 /$ bjc. 12112 .

Collett, N., Pugh, K., Waite, F., \& Freeman, D. (2016). Negative cognitions about the self in patients with persecutory delusions: An empirical study of self compassion, self stigma, schematic beliefs, self esteem, fear of madness, and suicidal ideation. Psychiatry Research, 239, 79-84. doi: 10.1016/j.psychres.2016.02.043.

Connell, M., Schweitzer, R., \& King, R. (2015). Recovery from first episode psychosis and recovering self: A qualitative study. Psychiatric Rehabilitation Journal, 38, 4, 359-364. doi:10.1037/prj0000077.

Crawford, J. \& Henry, J. (2004). The Positive and Negative Affect Schedule (PANAS): Construct validity, measurement properties and normative data in a large non-clinical sample. British Journal of Clinical Psychology, 43, 3, 245-265. doi: 10.1348/0144665031752934.

Diener, E., Emmons, R., Larsen, R., \& Griffin, S. (1985). The Satisfaction With Life Scale. Journal of Personality Assessment, 49, 1, 71-75. doi: 10.1207/s15327752jpa4901_13.

Diener, E., Heintzelman, S. J., Kushlev, K., Tay, L., Wirtz, D., Lutes, L. D., \& Oishi, S. (2017). Findings all psychologists should know from the new science on subjective wellbeing. Canadian Psychology, 58, 2, 87. doi: $10.1037 /$ cap0000063.

Douglass, R, P. \& Duffy, R. D. (2015). Strengths use and life satisfaction: A moderated mediation approach. Journal of Happiness Studies, 16, 3, 619-632. doi: 10.1007/s10902-014-9525-4.

Dunn, B. D. (2017). Opportunities and challenges for the emerging field of positive emotion regulation: A commentary on the special edition on positive emotions and cognitions in clinical psychology. Cognitive Therapy and Research, 41, 3, 469-478. doi: 10.1007/s10608-017-9831-3.

Ellett, L. \& Chadwick, P. (2007). Paranoid cognitions, failure, and focus of attention in college students. Journal of Cognition and Emotion, 21, 3, 558-576. doi: 10.1080/02699930600758155.

Fowler, D., Freeman, D., Smith, B. E. N., Kuipers, E., Bebbington, P., Bashforth, H., Coker, S., \& Garety, P. (2006). The Brief Core Schema Scales (BCSS): psychometric properties and associations with paranoia and grandiosity in non-clinical and psychosis samples. Psychological Medicine, 36, 6, 749-759. doi: 10.1017/S0033291706007355.

Freeman, D., Garety, P. A., Kuipers, E., Fowler, D., \& Bebbington, P. E. (2002). A cognitive model of persecutory delusions. British Journal of Clinical Psychology, 41, 4, 331-347. doi: 10.1348/014466502760387461.

Freeman, D., Pugh, K., Dunn, G., Evans, N., Sheaves, B., Waite, F., Cernis, E., Lister, R., \& Fowler, D. (2014). An early Phase II randomised controlled trial testing the effect on persecutory delusions of using CBT to reduce negative cognitions about the self: the potential benefits of enhancing self confidence. Schizophrenia Research, 160, 1, 186-192. doi: 10.1016/j.schres.2014.10.038.

Freeman, D., Garety, P. A., Bebbington, P. E., Smith, B., Rollinson, R., Fowler, D., Kuipers, E., Katarzyna R., \& Dunn, G. (2005). Psychological investigation of the structure of paranoia in a non-clinical population. The British Journal of Psychiatry, 186, 5, 427-435. doi: 10.1192/bjp.186.5.427.

Gander, F., Proyer, R. T., Ruch, W., \& Wyss, T. (2013). Strength based positive interventions: Further evidence for their potential in enhancing wellbeing and alleviating depression. Journal of Happiness Studies, 14 ,4, 1241-1259. doi: 10.1007/s10902-012-9380-0.

Giesler, R. B., Josephs, R. A., \& Swann, W. B. (1996). Self verification in clinical depression: The desire for negative evaluation. Journal of Abnormal Psychology, 105, 3, 358.-368. doi: 10.1037/0021-843X.105.3.358. 
Govindji, R. \& Linley, P. A. (2007). Strengths use, self concordance and wellbeing: Implications for strengths coaching and coaching psychologists. International Coaching Psychology Review, 2, 2, 143-153.

Green, C. E. L., Freeman, D., Kuipers, E., Bebbington, P., Fowler, D., Dunn, G., \& Garety, P. A. (2008). Measuring ideas of persecution and social reference: The Green et al. Paranoid Thought Scales (GPTS). Psychological Medicine, 38, 1, 101-111. doi:10.1017/S0033291707001638.

Hall, P. L. \& Tarrier, N. (2003). The cognitive behavioural treatment of low self esteem in psychotic patients: a pilot study. Behaviour Research Therapy, 41, 3, 317-332. doi: 10.1016/S0005-7967(02)00013-X.

Hayes, A. (2012). PROCESS: A versatile computational tool for observed variable mediation, moderation, and conditional process modeling [White paper]. Retrieved from http://www.afhayes.com/ public/process2012.pdf.

Hayes, A. (2013). Introduction to mediation, moderation, and conditional process analysis: A regression based approach. New York: Guilford Press.

Hefferon, K. \& Boniwell, I. (2011). Positive psychology theory, research and applications. New York: Open University Press.

Higgins, A. \& McBennett, P. (2007). The petals of recovery in a mental health context. British Journal of Nursing, 16, 14, 852-856. doi 10.12968/bjon.2007.16.14.24322.

Higher Education Statistics Agency (2018). Higher Education Student Statistics: UK, 2016/17 Student numbers and characteristics Retrieved from https://www.hesa.ac.uk/news/11-01-2018/sfr247-highereducation-student-statistics/numbers.

Hutton, P. (2016). Positive clinical psychology and the promotion of happiness, compassion and autonomy in people with psychosis. In A. Wood, Johnson J (Ed.) The Wiley Handbook of Positive Clinical Psychology, (pp 245-260). Oxford: Wiley.

Jack, A. \& Egan, V. (2018). Childhood bullying, paranoid thinking and the misappraisal of social threat: trouble at school. School mental health, 10, 1, 26-34. doi: 10.1007/s12310-017-9238-z.

Jaya, E. S., Ascone, L., \& Lincoln, T. M. (2017). A longitudinal mediation analysis of the effect of negative self-schemas on positive symptoms via negative affect. Psychological Medicine, 1-11 doi: 10.1017/S003329171700277X.

Keyes, C. \& Martin, C. (2017). The complete state model of mental health. In M. Slade (Ed.) Wellbeing Recovery and Mental Health (pp 86-99). Cambridge: Cambridge University Press.

Kuyken, W., Padesky, C, A., \& Dudley, R. (2009). Collaborative case conceptualization: Working effectively with clients in Cognitive Behavioural Therapy. London: Guilford Press.

Lester, H., Marshall, M., Jones, P., Fowler, D., Amos, T., Khan, N., \& Birchwood, M. (2011). Views of young people in early intervention services for first episode psychosis in England. Psychiatric Services, 62, 8, 882-887. doi: 10.1176/ps.62.8.pss6208_0882.

Lumley, T., Diehr, P., Emerson, S., \& Chen, L. (2002). The importance of the normality assumption in large public health data sets. Annual Review of Public Health, 23, 151-169. doi: 10.1146/annurev.publhealth.23.100901.140546.

Magyar-Moe, J. (2009). Therapist's guide to positive psychological interventions. San Diego: Elsevier Academic Press.

Mankiewicz, P., Gresswell, D., \& Turner, C. (2013). Happiness in severe mental illness: exploring subjective wellbeing of individuals with psychosis and encouraging socially inclusive multidisciplinary practice. Mental Health and Social Inclusion, 17, 1, 27-34. doi: 10.1108/20428301311305287.

Mark W. \& Toulopoulou, T. (2016). Psychometric properties of Community Assessment of Psychic Experiences: Review and meta analyses. Schizophrenia Bulletin, 42, 1. 34-44. doi: 10.1093/schbul/sbv088.

Matos, M., Pinto Gouveia, J., \& Gilbert, P. (2013). The effect of shame and shame memories on paranoid ideation and social anxiety. Clinical psychology E psychotherapy, 20, 4, 334-349. doi: 10.1002/cpp.1766.

Maxwell, S. E. \& Cole, D. A. (2007). Bias in cross sectional analyses of longitudinal mediation. Psychological Methods, 12, 1, 23. doi: 10.1037/1082-989X.12.1.23.

Meyer, P. S., Johnson, D. P., Parks, A., Iwanski, C., \& Penn, D. L. (2012). Positive living: A pilot study of group positive psychotherapy for people with schizophrenia. The Journal of Positive Psychology, 7, 3, 239-248. doi: 10.1080/17439760.2012.677467. 
Mills, A., Gilbert, P., Bellew, R., McEwan, K., \& Gale, C. (2007). Paranoid beliefs and self criticism in students. Clinical Psychology \& Psychotherapy, 14, 5, 358-364. doi: 10.1002/cpp.537.

Mongrain, M. \& Anselmo-Matthews, T. (2012). Do positive psychology exercises work? A replication of Seligman et al. 2005. Journal of Clinical Psychology, 68, 4, 382-389. doi: 10.1002/jclp.21839.

Newcastle University (2018) Student statistics. Retrieved from http://www.ncl.ac.uk (Accessed 03/04/2018)

Pavot, W. \& Diener, E. (1993). Review of the Satisfaction with Life Scale. Psychological Assessment, 5, 2, 164172. doi:10.1080/17439760701756946.

Payton, A. (2009). Mental health, mental illness and psychological distress: same continuum or distinct phenomena? Journal of Health and Social Behaviour, 50, 2, 213-227. doi: 10.1177/002214650905000207.

Peterson, C. \& Seligman, M. E., (2004). Character strengths and virtues: A handbook and classification. New York: Oxford University Press.

Peterson, C. (2004). Brief Strengths Test. Retrieved from: http://www.authentichappiness. sas.upenn.edu/. (Accessed 06/02/2018).

Peterson, C. (2006). A primer in positive psychology. New York: Oxford University Press.

Pfeifer, J, H., Masten, C, L., Borofsky, L, A., Dapretto, M., Fuligni, A, J., \& Liberman, M, D. (2009). Neural correlates of direct and reflected self appraisals in adolescents and adults: When social perspective taking informs self perception. Child Development, 80, 4, 1016-1038 doi 10.1111/j.1467-8624.2009.01314.x.

Pietrowsky, R. \& Mikutta, J. (2012). Effects of positive psychology interventions in depressive patients -A randomized control study. Psychology, 3, 12, 1067-1073. doi: 10.4236/psych.2012.312158.

Pinto Gouveia, J., Matos, M., Castilho, P., \& Xavier, A. (2014). Differences between depression and paranoia: the role of emotional memories, shame and subordination. Clinical psychology $\mathcal{E}$ psychotherapy, 21, 1, 49-61. doi: 10.1002/cpp.1818.

Proyer, R. T., Gander, F., Wellenzohn, S., \& Ruch, W. (2015). Strengths based positive psychology interventions: a randomized placebo controlled online trial on long term effects for a signature strengths vs. a lesser strengths intervention. Frontiers in Psychology, 6, 456. doi: 10.3389/fpsyg.2015.00456.

Rankin, W. M. (2015). Exploring Relationships among Strengths Use, Spirituality, Religion and Positive Mental Health of College Attending Emerging Adults (Unpublished doctoral dissertation). Ohio University, Ohio.

Rashid, T. (2015). Positive psychotherapy: A strength based approach. The Journal of Positive Psychology, 10, 1, 25-40. doi: 10.1080/17439760.2014.920411.

Sax, K. W., Strakowski, S. M., Keck, P. E., Upadhyaya, V. H., West, S. A., \& McElroy, S. L. (1996). Relationships among negative, positive, and depressive symptoms in schizophrenia and psychotic depression. The British Journal of Psychiatry, 168, 1, 68-71. doi: 10.1192/bjp.168.1.68.

Schrank, B., Brownell, T., Jakaite, Z., Larkin, C., Pesola, F., Riches, S., \& Slade, M. (2016). Evaluation of a positive psychotherapy group intervention for people with psychosis: pilot randomised controlled trial. Epidemiology and Psychiatric Sciences, 25, 3. 235-246. doi: 10.1017/S2045796015000141.

Seligman, M. E. \& Csikszentmihalyi, M. (2000). Positive psychology: An introduction. American Psychologist, 55, 1, 5-14. doi: 10.1037/0003-066X.55.1.5.

Seligman, M. E., (2002). Authentic happiness. New York: Simon \& Schuster.

Seligman, M, E., Steen T., Park, N., \& Peterson, C. (2005). Positive psychology progress: empirical validation of interventions. American Psychologist, 60, 5, 410-421. doi: 10.1037/0003-066X.60.5.410.

Seligman, M. E., Rashid, T., \& Parks, A. (2006). Positive psychotherapy. American Psychologist; 61, 8, 774778. doi: 10.1037/0003-066X.61.8.774.

Seligman, M. E. (2015). Chris Peterson's unfinished masterwork: The real mental illnesses. The Journal of Positive Psychology, 10, 1, 3-6. doi: 10.1080/17439760.2014.

Sims, A., Barker, C., Price, C., \& Fornells-Ambrojo, M. (2015). Psychological impact of identifying character strengths in people with psychosis. Psychosis, 7, 2, 179-182. doi: 10.1080/17522439.2014.925485.

Smith, B., Fowler, D. G., Freeman, D., Bebbington, P., Bashforth, H., Garety, P., Dunn, G., \& Kuipers, E. (2006). Emotion and psychosis: links between depression, self esteem, negative schematic beliefs and delusions and hallucinations. Schizophrenia Research, 86, 1-3, 181-188. doi:10.1016/j.schres.2006.06.018. 
Sousa, M., Barreto Carvalho, C., Da Motta, C., Cabral, J., Pereira, V., Caldeira, S., \& Peixoto, E. B. (2015). Characterization and predictors of paranoid ideation in youths. International Journal of Psychological and Behavioral Sciences, 9, 2, 1694-1701. doi: 10.5281/zenodo.1107097.

Tai, S., Kinderman, P., Choudray, S., Gillmer, B., Gwilliam, P., Hanna, J., Lavender, R., Pilgrim, D., Shepherd, G., \& Taylor, J. (2009). Psychological health and well-being: A new ethos and a new service structure for mental health. Leicester: British Psychological Society.

Tiernan, B., Tracey, R., \& Shannon, C. (2014). Paranoia and self concepts in psychosis: a systematic review of the literature. Psychiatry Research, 216, 3, 303-313. doi: 10.1016/j.psychres.2014.02.003.

Tse, S., Tsoi, E. W., Hamilton, B., O'Hagan, M., Shepherd, G., Slade, M., \& Petrakis, M. (2016). Uses of strength based interventions for people with serious mental illness: A critical review. International Journal of Social Psychiatry, 62, 3, 281-291. doi: 10.1177/0020764015623970.

Turner, D. T., Van Der Gaag, M., Karyotaki, E., \& Cuijpers, P. (2014). Psychological interventions for psychosis: a meta analysis of comparative outcome studies. American Journal of Psychiatry, 171, 5, 523538. doi: 10.1176/appi.ajp.2013.13081159.

Van Os, J., Verdoux, H., \& Hanssen, M. (1999). CAPE-42. Retrieved from http://cape42.homestead.com/. (Accessed 01/04/2018).

Vorontsova, N., Garety, P., \& Freeman, D. (2013). Cognitive factors maintaining persecutory delusions in psychosis: The contribution of depression. Journal of Abnormal Psychology, 122, 4, 1121.-1131. doi: 10.1037/a0034952.

Watson, D., Clark, L. A., \& Tellegen, A. (1988). Development and validation of brief measures of positive and negative affect: the PANAS scales. Journal of Personality and Social Psychology, 54, 6, 1063-1070.

Wood, A. M., Linley, P. A., Maltby, J., Kashdan, T. B., \& Hurling, R. (2011). Using personal and psychological strengths leads to increases in wellbeing over time: A longitudinal study and the development of the strengths use questionnaire. Personality and Individual Differences, 50, 1, 15-19. doi: 10.1016/j.paid.2010.08.004. 